\title{
GRUPO DE ESTUDO: RELATO DE EXPERIÊNCIA SOBRE A MEDIAÇÃO VIRTUAL DURANTE A PANDEMIA DA COVID-19
}

\author{
STUDY GROUP: EXPERIENCE REPORT OF VIRTUAL MEDIATION DURING THE COVID-19 \\ PANDEMIC
}

\section{GRUPO DE ESTUDIO: RELATO DE EXPERIENCIA EN MEDIACIÓN VIRTUAL DURANTE LA PANDEMIA COVID-19}

\author{
Geovânia de Souza Andrade Maciel ${ }^{1}$ \\ Alyne Pereira de Oliveira ${ }^{2}$
}

\begin{abstract}
RESUMO
O presente artigo refere-se a um relato de experiência acerca de uma das atividades realizadas por meio do Projeto de Mediação Virtual ${ }^{3}$. Trata-se de um grupo de estudo virtual realizado com alunos dos segundos anos de uma instituição de ensino de Ji-Paraná e de outra instituição pública de ensino situada na cidade vizinha, Ouro Preto do Oeste. O projeto teve como objetivo promover o aprofundamento do processo de aprendizagem por intermédio do ensino remoto, em decorrência da Pandemia da COVID-19. Como aporte teórico a criação do grupo pautou-se nos estudos de Freire (1996), Dayrell (2007) e em especial, na abordagem dos pesquisadores Murphy e Lick (2005). Isto posto, a atividade em pauta realizou-se por meio de um grupo no WhatsApp, onde os 57 participantes formaram uma comunidade com ênfase na troca de conhecimentos. Os resultados do grupo de estudo mostraram que a sociabilidade no ensino é fundamental para motivar o processo educacional e promover uma aprendizagem colaborativa.
\end{abstract}

PALAVRAS-CHAVE: Grupo de estudo. Mediação virtual. Ensino remoto. Aprendizagem colaborativa. Sociabilidade.

Submetido em: 29/05/2021- Aceito em: 05/10/2021- Publicado em: 13/10/2021

\footnotetext{
${ }^{1}$ Mestra em Letras pela Universidade Federal de Rondônia (UNIR) e docente de Língua Portuguesa e Literatura do Instituto federal de Rondônia, Campus Ji-Paraná. Membro do Grupo de Estudos em Leitura, Linguagens e Identidade Cultural - GELLIC. E-mail: geovania.maciel@ifro.edu.br

${ }^{2}$ Estudante do $3^{\circ}$ Ano, curso Técnico de Informática Integrado ao Ensino Médio, bolsista pelo Projeto de mediação virtual (IFRO). E-mail: alynepereiradeoliveira@gmail.com

${ }^{3}$ Diz respeito ao Projeto PROBEN MEDVIRTUAL, executável no ano de 2020 pelo Edital n. 03/2020, por meio da Pró-Reitoria de Ensino - PROEN - no âmbito do Instituto Federal de Educação, Ciência e Tecnologia de Rondônia - IFRO.
} 


\section{ABSTRACT}

This article refers to an experience report about one of the activities developed through the Virtual Mediation Project. It is a virtual study group carried out with students of the second years of a teaching institution in JiParaná and another public educational institution located in the neighboring city, Ouro Preto do Oeste. The project aimed to promote the deepening of the learning process through remote teaching, as a result of the COVID-19 Pandemic. As a theoretical contribution, the creation of the group is based on the studies of Freire (1996), Dayrell (2007) and in particular, on the approach of researchers Murphy and Lick (2005). That said, the activity on the agenda was carried out through a group on WhatsApp, where the 57 participants formed a community with an emphasis on the exchange of knowledge. The results of the study group showed that the sociability in teaching is fundamental to motivate the educational process and promote collaborative learning.

KEYWORDS: Study group. Virtual mediation. Remote Learning. Collaborative learning. Sociability.

\section{RESUMEN}

Este artículo hace referencia a un relato de experiencia sobre una de las actividades realizadas a través del Proyecto de Mediación Virtual. El objeto es un grupo de estudio virtual realizado con estudiantes de segundo año de una institución de enseñanza en Ji-Paraná y otra institución educativa pública ubicada en la ciudad vecina, Ouro Preto do Oeste. El proyecto tuvo como objetivo promover la profundización del proceso de aprendizaje a través de la enseñanza a distancia, como consecuencia de la Pandemia COVID-19. Como aporte teórico, la creación del grupo se basa en los estudios de Freire (1996), Dayrell (2007) y en particular, en el enfoque de los investigadores Murphy y Lick (2005). Dicho esto, la actividad de la agenda se realizó a través de un grupo en WhatsApp, en que los 57 participantes conformaron una comunidad con énfasis en el intercambio de conocimientos. Los resultados del grupo de estudio mostraron que la sociabilidad en la enseñanza es fundamental para motivar el proceso educativo y promover el aprendizaje colaborativo.

PALABRAS CLAVE: Grupo de estudio. Mediación virtual. Enseñanza remota. Aprendizaje colaborativo. Sociabilidad.

\section{INTRODUÇÃO}

As instituições de ensino têm procurado diversas maneiras de transformar a educação e estimular o aprendizado dos estudantes. Essa busca torna-se cada vez mais árdua, visto que as escolas não conseguem acompanhar as constantes mudanças e demandas da sociedade atual.

Em especial o ano 2020 tornou essa tarefa ainda mais difícil, pois diante da Pandemia da COVID-19, as instituições de ensino ficaram impossibilitadas em realizar suas atividades de modo presencial e a tecnologia passou a ser um instrumento fundamental para a educação remota. Dessa maneira, a execução de uma comunidade estudantil com metodologia participativa surgiu como ferramenta estratégica a efetuar-se por meio da criação de um Grupo de Estudo no aplicativo de mensagens instantâneas e chamadas de voz, WhatsApp. O grupo passou a ser administrado por uma estudante, na função de mediadora virtual, que sob a 
orientação de uma professora de Língua Portuguesa e Literatura, direcionou parte dos trabalhos do grupo. Como público alvo das atividades, participaram estudantes do segundo ano do Ensino Médio, de uma instituição de ensino da cidade de Ji Paraná, e alguns selecionados de uma escola estadual da cidade vizinha, Ouro Preto do Oeste.

De acordo com Bill Gates, mesmo que a tecnologia promova a interação entre os jovens a estudarem juntos, o professor ainda é o recurso mais importante:

Há um temor frequentemente expresso de que a tecnologia substitua os professores. Posso dizer enfática e inequivocamente que não. A estrada não vai substituir ou desvalorizar nenhum dos talentos educacionais humanos necessários aos desafios do futuro: professores interessados, administradores criativos, pais envolvidos e, é claro, alunos diligentes. A tecnologia será essencial, porém, no futuro papel dos professores. (GATES, 1995, p. 232)

Sob a ótica da assertiva desse autor americano, percebeu-se que a participação da professora orientadora e a atuação da mediadora virtual foram fundamentais para garantir que o Grupo de Estudo não prosseguisse por caminho tortuoso.

\section{Grupo de estudo como ferramenta do ensino remoto}

No atual cenário de isolamento social e suspensão das atividades presenciais as relações pessoais foram estritamente limitadas, o que tem gerado o agravamento dos sintomas de alguns transtornos mentais (BARROS et al. 2020). O educador Paulo Freire (1996), já havia destacado a importância em criar laços de amizade e convivência em meio educacional em prol de oportunizar maior autonomia aos estudantes, ajudando-os a "a reconhecer-se como arquiteto de sua própria prática cognoscitiva", e assim conseguir assumir a autoria "do conhecimento do objeto":

Como prática estritamente humana jamais pude entender a educação como uma experiência fria, sem alma, em que os sentimentos e as emoções, os desejos, os sonhos devessem ser reprimidos por uma espécie de ditadura racionalista. (FREIRE, 1996, p. 47) 
Sendo assim, o grupo de estudo, por meio da troca de mensagens, tornou-se um agente promotor de acolhimento, socialização e autonomia entre os alunos, aproximando-os por um objetivo em comum: o compartilhamento de conhecimentos diversos. Vale frisar que a sociabilidade entre grupos juvenis é característica enfatizada por muitos estudiosos, dentre os quais Dayrell assevera o seguinte:

\begin{abstract}
A sociabilidade tende a ocorrer em fluxo cotidiano, seja no intervalo entre as "obrigações", o ir-e-vir da escola ou do trabalho, seja nos tempos livres e de lazer, na deambulação pelo bairro ou pela cidade. (...). Enfim, podemos afirmar que a sociabilidade, para os jovens, parece responder às suas necessidades de comunicação, de solidariedade, de democracia, de autonomia, de trocas afetivas e, principalmente, de identidade. (DAYRELL, 2007, p. 1111)
\end{abstract}

Outrossim, a metodologia do grupo de estudo criado, baseou-se na abordagem proposta pelos pesquisadores Murphy e Lick (2005), o que permitiu aos alunos trocarem conhecimentos e compartilharem materiais de estudo, sendo eles autorais ou não. Essa prática consentiu também a troca de saberes e possibilitou verificar determinado assunto sob outra perspectiva.

Vale lembrar que muitas pesquisas apresentam os grupos de estudos como ferramenta utilizada na melhoria do processo de ensino-aprendizagem. Conforme as pesquisas de Murphy e Lick (2005) os grupos de estudos procuram dirimir as dificuldades dos indivíduos e das instituições, de maneira simultânea e organizada, priorizando a colaboração do professor no intuito de tornar alunos mais hábeis, competentes e autônomos. Grupo de estudos pode ser definido também como ambiente onde pessoas com semelhantes realidades - estudantes de mesmo grau e/ou objetivos - se reúnem para trocar conhecimentos e esclarecer dúvidas, resultando assim em sensação de pertencimento entre os participantes.

Segundo o professor Rafael Ernesto, da instituição UNINASSAU (2020), um grupo de estudos permite que alunos se desenvolvam de maneira autônoma, além de fugir da normalidade da rota acadêmica, mostrando-se um ótimo instrumento para complementar a formação de forma dinâmica e diferenciada; igualmente os participantes se tornam aptos a demonstrarem espírito de liderança.

Nesse sentido, a realização do estudo em grupo pelo WhatsApp teve uma notável relevância para o processo educacional durante o ensino remoto, como se observará a seguir, no relato 
dessa atividade que buscou aproximar e familiarizar estudantes do ensino médio com a perspectiva de busca pelo conhecimento coletivo.

\section{RELATO DE EXPERIÊNCIA}

Seguindo a proposta inicial do projeto, nos dias 5 e 6 de setembro de 2020, foram enviados os convites para que os estudantes de Ji-Paraná conhecessem a proposta do Grupo de Estudo pelo WhatsApp. Aos alunos da escola da cidade de Ouro Preto, a proposta foi feita, inicialmente, à professora titular da turma, que escolheu 13 estudantes para participarem e já no dia 8 iniciaram-se as atividades no grupo de estudo.

Primeiramente, foram enviados textos, sendo um de apresentação do grupo e outro de motivação para os estudos. Na sequência, os alunos além de receberem os materiais dispostos pela estudante bolsista, eram constantemente estimulados a tirarem suas dúvidas e enviarem conteúdos que considerassem pertinentes aos interesses do grupo de estudo.

Durante a execução das atividades, assuntos relevantes foram abordados no grupo de WhatsApp, priorizando-se colocar em prática os cincos princípios $\mathrm{WFSG}^{4}$ apontados por Murphy e Lick (2005, p. 13-15), conforme consta sintetizado no quadro abaixo:

\footnotetext{
${ }^{4}$ O sistema WFSG - Whole-Faculty Study Groups - é uma abordagem integrada de trabalho, autodirigida que procura auxiliar professores a construir comunidades de alunos mais autônomos, e tais docentes projetam, assim, melhorar escolas e aumentar a aprendizagem dos alunos por meio do trabalho grupal (MURPHY; LICK, 2005, p. 2)
} 
Quadro 1: Cinco Princípios WFSG

\begin{tabular}{|c|c|}
\hline Cinco Princípios dos autores & $\begin{array}{l}\text { Aplicação do princípio no Grupo de estudo } \\
\text { virtual }\end{array}$ \\
\hline $\begin{array}{l}\text { 1. Students are first } \\
\text { Os estudantes em primeiro lugar: Procura-se } \\
\text { examinar rotineiramente os alunos estudando de } \\
\text { forma colaborativa, ouvi-los, prestar atenção nos } \\
\text { seus anseios. }\end{array}$ & $\begin{array}{l}\text { O interesse dos participantes do grupo foi priorizado. A } \\
\text { participação dos estudantes no grupo e a resolução do } \\
\text { questionário proposto em formulário on-line foram itens } \\
\text { que auxiliaram a mediadora nessa tarefa de compreender o } \\
\text { que o grupo almejava estudar. }\end{array}$ \\
\hline $\begin{array}{l}\text { 2. Everyone participates } \\
\text { Todos participam. } \\
\text { Os autores direcionam a pesquisa para grupo de } \\
\text { estudo de professores, afirmando que cada pessoa } \\
\text { é membro de um grupo de três a cinco membros } \\
\text { de acordo com suas especificidades. Inclusive, } \\
\text { menciona a participação de professores } \\
\text { assistentes, pessoal não docente e diretores. }\end{array}$ & $\begin{array}{l}\text { O grupo no WhatsApp abrangeu um número maior de } \\
\text { membros (57), contudo todos tinham direito a participar } \\
\text { ativamente no compartilhamento dos materiais, fazendo } \\
\text { questionamentos e respondendo questões realizadas por } \\
\text { outros estudantes. }\end{array}$ \\
\hline $\begin{array}{l}\text { 3. Leadership is shared } \\
\text { Liderança compartilhada. } \\
\text { Cada membro de um grupo de estudo atua como } \\
\text { líder rotativamente. }\end{array}$ & $\begin{array}{l}\text { Como o prazo de execução do projeto de mediação era de } \\
\text { apenas } 5 \text { meses, tivemos a mediadora como } \\
\text { administradora do grupo que ficou responsável pela } \\
\text { organização semanal dos assuntos que seriam enviados. } \\
\text { Todavia, todos integrantes tinham livre atuação para } \\
\text { postagens de conteúdos disciplinares que considerassem } \\
\text { relevantes ao grupo. }\end{array}$ \\
\hline $\begin{array}{l}\text { 4. Responsibility is equal } \\
\text { Responsabilidades iguais. } \\
\text { Todos têm a mesma responsabilidade quanto ao } \\
\text { trabalho no grupo. As normas são estabelecidas } \\
\text { na primeira reunião e todos os membros são } \\
\text { responsáveis por aderir tais normas. }\end{array}$ & $\begin{array}{l}\text { Conforme descrição das regras expostas desde o primeiro } \\
\text { dia de criação do grupo, tivemos: } \\
\text { "No grupo vocês podem: } \\
\text {-Tirar dúvidas em relação a qualquer matéria. Qualquer } \\
\text { participante do grupo pode responder a dúvida; } \\
\text { - Compartilhar materiais de estudo referentes ao conteúdo } \\
\text { do segundo ano produzidos por vocês: resumos, mapas } \\
\text { mentais, etc; } \\
\text { - Interagir com os participantes; } \\
\text { - Promover discussões sobre temas relevantes; } \\
\text {-Compartilhar dicas de estudo, filmes e documentários." }\end{array}$ \\
\hline $\begin{array}{l}\text { 5. The work is public } \\
\text { O trabalho do grupo é público. } \\
\text { Como os autores direcionam os princípios para } \\
\text { grupos de docentes, cita que os grupos de estudos } \\
\text { automaticamente podem estar compartilhando os } \\
\text { trabalhos produzidos em seu grupo (planos de } \\
\text { ação, resumos, agendas de reuniões...) com os } \\
\text { demais grupos da escola. }\end{array}$ & $\begin{array}{l}\text { Todo trabalho compartilhado no grupo (produzido ou não } \\
\text { pelos participantes) poderia ser compartilhado em outras } \\
\text { redes de compartilhamentos, assim abrangendo uma maior } \\
\text { interação na troca de conhecimento. }\end{array}$ \\
\hline
\end{tabular}

Fonte: Elaborado pela pesquisadora a partir de Murphy e Lick (2005, p. 13-15) 
Pode-se afirmar que, seguindo os princípios expostos no quadro anterior, foi possível oportunizar a todos os participantes a construção de um sentimento de pertencimento ao grupo e um maior envolvimento no processo de ensino-aprendizagem on-line. Assim, foi notável a participação colaborativa de todos os integrantes do grupo.

\section{A função colaborativa do mediador virtual e demais participantes do grupo}

Apesar da Educação a Distância $(\mathrm{EaD})$ ter se iniciado de maneira sistemática há algumas décadas em nosso país, a definição de termos como "mediador virtual" ainda demanda de estudos mais aprofundados quando direcionado a um ensino em contexto pandêmico. Por ora, o relato de experiência em questão reflete a mediação virtual exercida por uma professora e uma aluna no desenvolvimento de atividades com estudantes do $2^{\circ}$ ano do Ensino Médio. Assim, a mediação virtual, nesse caso específico, pode ser definida como práticas interventivas pedagógicas que foram realizadas durante o percurso de interatividade ocorrido em contexto virtual (WhatsApp), visando a construção de um processo educativo colaborativo, apesar das dificuldades impostas pelo isolamento social.

Vale ressaltar que diante da suspensão das aulas ocorridas em 2019 devido à pandemia do Coronavírus, o que passou a fazer parte das instituições de ensino foi a prática do ensino remoto. Este se assemelha ao EaD apenas no que diz respeito a sua mediação pela tecnologia, contudo quanto aos princípios, é necessário asseverar que permaneceram os mesmos já vivenciados no contexto de ensino presencial.

Segundo Santos (2009):

Nas práticas convencionais de EAD, temos a auto-aprendizagem como característica fundante, ou seja, o cursista recebe o material do curso com instruções que envolvem conteúdos e atividades, elabora sua produção individual retornando-a, via canais de feedback, ao professor tutor. Assim a aprendizagem é construída e mediada pelo material didático produzido à luz de um desenho instrucional. A instrução unidirecional é o centro do processo. O sujeito aprende solitário e no seu tempo e o material didático estático tem um papel muito importante. (SANTOS, 2009, p. 5665) 
Já o ensino remoto on-line veio como uma medida de emergência para tentar dirimir o caos ocasionado pela pandemia. Sem um plano educacional, os professores tiveram que adaptar suas aulas, conteúdos e instrumentos didáticos para continuar o processo de ensino mesmo que com empecilhos na aprendizagem. Assim, o uso das diversas plataformas on-line e outros recursos digitais passaram a fazer parte de forma imperiosa no planejamento docente.

As instituições de ensino passaram de um dia para o outro a refletir em sua prática acerca do significado de educação on-line que Santos $(2009$, p. 5658) já definia como um fenômeno da cibercultura que avançava com relação a EaD. Em outras palavras, é possível afirmar que enquanto a Ead direciona um processo de aprendizagem mais fragmentado na relação professor e aluno, o ensino on-line potencializa práticas educacionais mais colaborativas por intermédio de interfaces digitais e corrobora para que os participantes envolvidos no processo estejam mais engajados.

É nesse contexto que a figura do mediador virtual se destaca com função colaborativa na busca pela interatividade grupal, apresentando uma postura organizada, promovendo estratégias para o aprofundamento e ampliação dos conteúdos apresentados. O acolhimento e a afetividade da mediadora virtual estudantil, juntamente com a mediação pedagógica da professora coordenadora, também se tornam atributos imprescindíveis para a partilha de conhecimento e o diálogo com todos do grupo.

Variados conteúdos disciplinares foram trazidos à discussão grupal por intermédio de elementos hipermidiáticos, como imagens e links de vídeos diversos, documentos de diferentes disciplinas, matérias com resumo de estudos, indicação de livros eletrônicos, sites e blogs com dicas de estudo, entre outros recursos audiovisuais digitais.

A princípio ficou perceptível que os participantes não se sentiam à vontade para falar no grupo e buscando melhorar a participação de todos foram realizados quizzes sobre tópicos do segundo ano do ensino médio, conforme ilustração a seguir: 
Figura 1: Print do Quiz Interativo

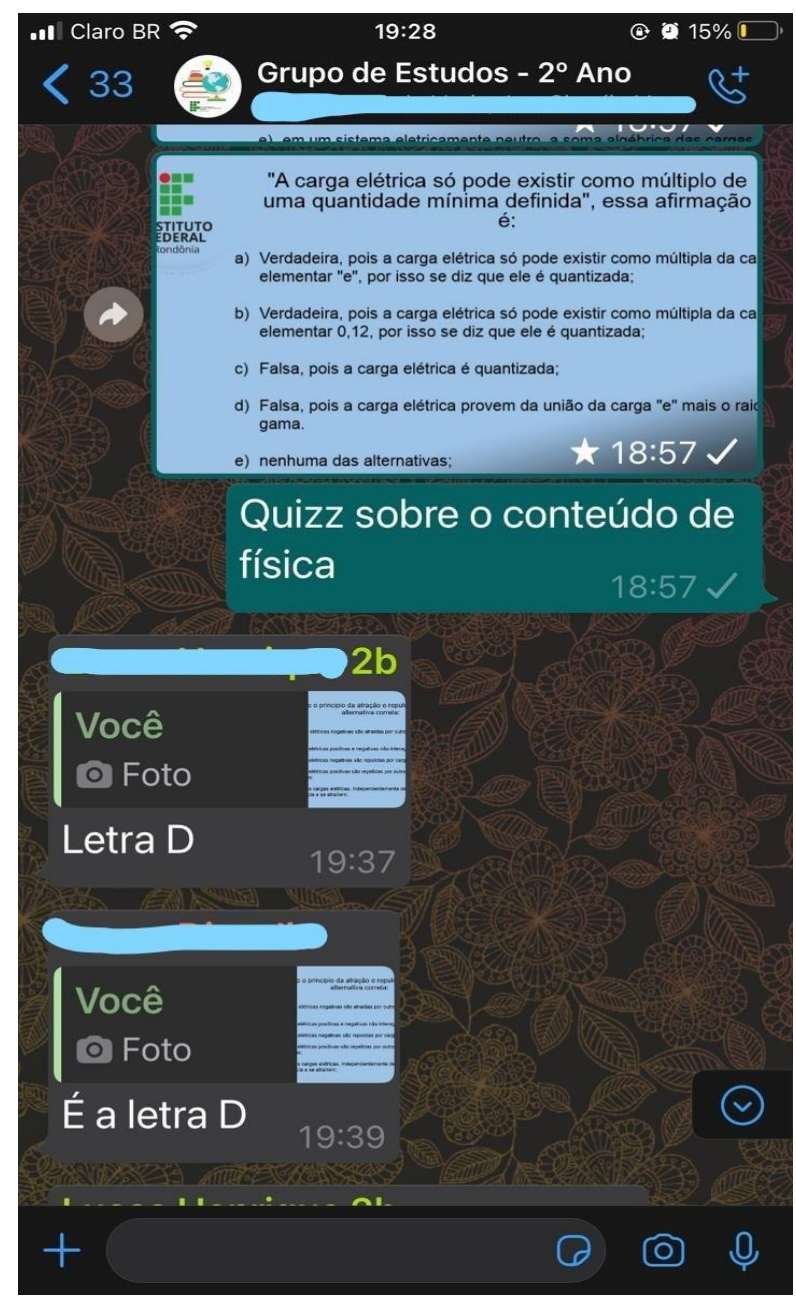

Fonte: As autoras, acervo da pesquisa.

Além disso, na busca em dinamizar cada vez mais os conteúdos propostos, as mediadoras virtuais (estudante e professora coordenadora) passaram a pesquisar filmes, documentários e livros a serem sugeridos no decorrer da exposição dos conteúdos disciplinares abordados. Os alunos envolvidos no projeto possuíam plena liberdade para se manifestarem, não apenas para tirar de dúvidas com relação ao conteúdo que estava com dificuldade, como também no envio de materiais complementares que considerassem relevantes, confirmando que essa experiência de estudo se sustentou em uma aprendizagem colaborativa. 
Conforme verifica-se no exemplo a seguir, um dos participantes sugere ao grupo o link para a inscrição do Exame Nacional do Amigo Edu (ENAE), disponibilizado pelo site Amigo Edu de maneira completamente gratuita aos candidatos inscritos. Outro estudante sugere a plataforma Kultive que oferece cursos on-line destinados a qualificação, sem custos para os usuários:

Figura 2: Participação colaborativa dos participantes

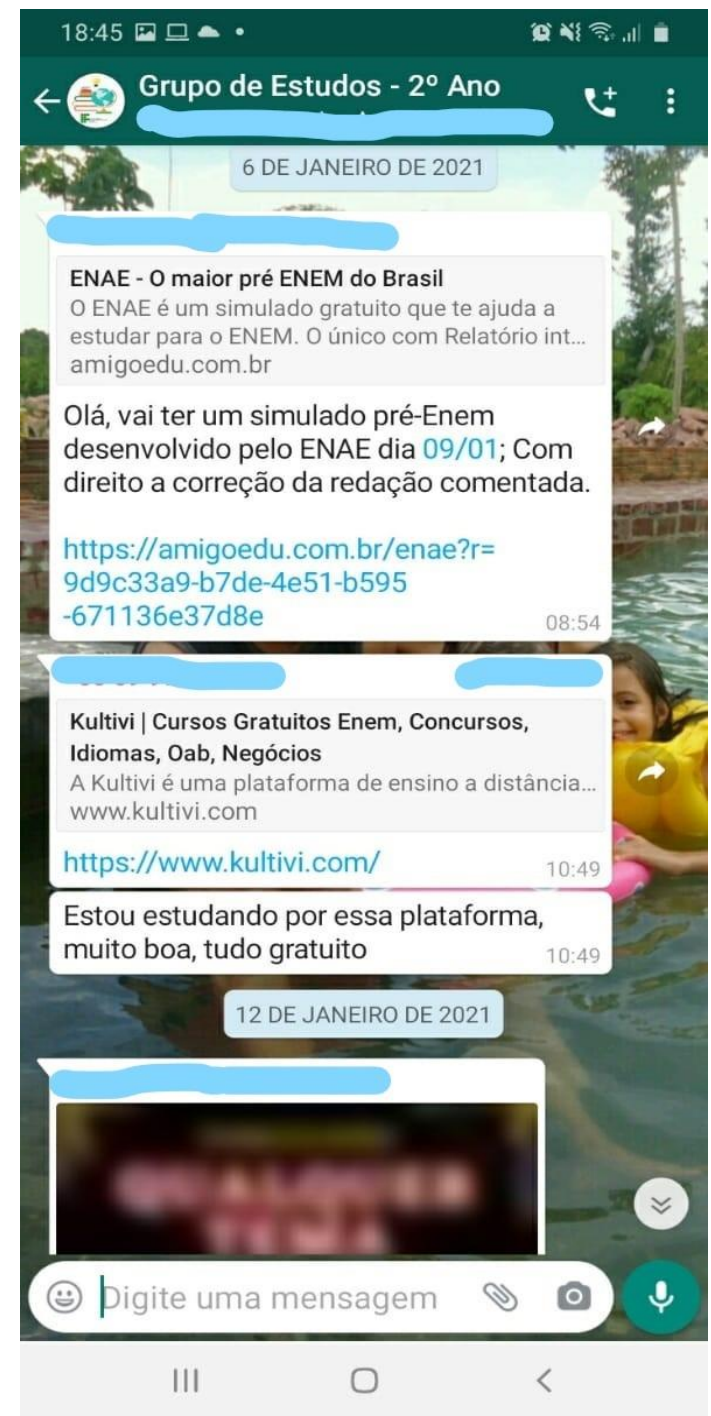

Fonte: As autoras, acervo da pesquisa.

Vale salientar que a formação do grupo de estudo, focou-se em uma aprendizagem colaborativa, ou seja, a parceria entre os participantes foi constante e todos contribuíram na execução das 


\section{Revista Docência e Cibercultura}

atividades. De tal forma, em poucas semanas tornou-se perceptível as habilidades de alguns aprendizes o que foi ao encontro da teoria gardneriana ao afirmar que as inteligências trabalham em harmonia, de tal forma que a autonomia se torna por vezes imperceptível. O autor sugere, assim, que "quando as lentes de observação adequadas são elaboradas, a natureza peculiar de cada inteligência emerge com suficiente (e não raro surpreendente) clareza" (GARDNER, 1994, p. 7), o que pode ser visível na participação dos estudantes ao explicar aos colegas do grupo o conteúdo na qual possuía conhecimento mais aprofundado.

Segundo Torres e Irala (2015), a aprendizagem colaborativa tem raízes em algumas das importantes tendências pedagógicas, como o Movimento da Escola Nova, o estudo de Piaget, a teoria sociocultural de Vygotsky, além da Pedagogia Progressista (TORRES; IRALA, 2015, p. 70).

Sob essa ótica acreditamos que a prática de mediação virtual aqui relatada, teve respaldo teórico vygotskyano, especialmente na abordagem em "captar" a zona de desenvolvimento proximal dos estudantes juvenis, objetivando "descobrir as relações reais entre o processo de desenvolvimento e a capacidade de aprendizado" (Vygotsky, 1991, p. 57). A ação se fez, alicerçada em uma prática educativa resultante da interação comunicacional - enquanto prática social também enfatizada por Vygotsky - na qual a ajuda entre todos os envolvidos priorizou uma aprendizagem coletiva. A figura do mediador virtual (seja o professor ou aprendizes mais experientes) se tornou importante instrumento para possibilitar a interconexão do conhecimento individual do estudante ao conhecimento curricular, de responsabilidade das instituições escolares.

Ademais, foram produzidos três questionários avaliativos por meio da ferramenta Formulário google, com questões abertas e fechadas, objetivando a percepção dos envolvidos com relação aos conteúdos apresentados ao grupo de Estudo, dando a oportunidade para que os estudantes julgassem a qualidade do trabalho em grupo e fizessem sugestões para abordagens de outros assuntos por conteúdos disciplinares. Por meio do resultado obtido nas avaliações dos estudantes, pode-se perceber que a participação no grupo de WhatsApp auxiliou e motivou os participantes a prosseguirem seus estudos remotamente. 


\section{Revista Docência e Cibercultura}

Figura 3: O que você achou da experiência em participar do grupo?

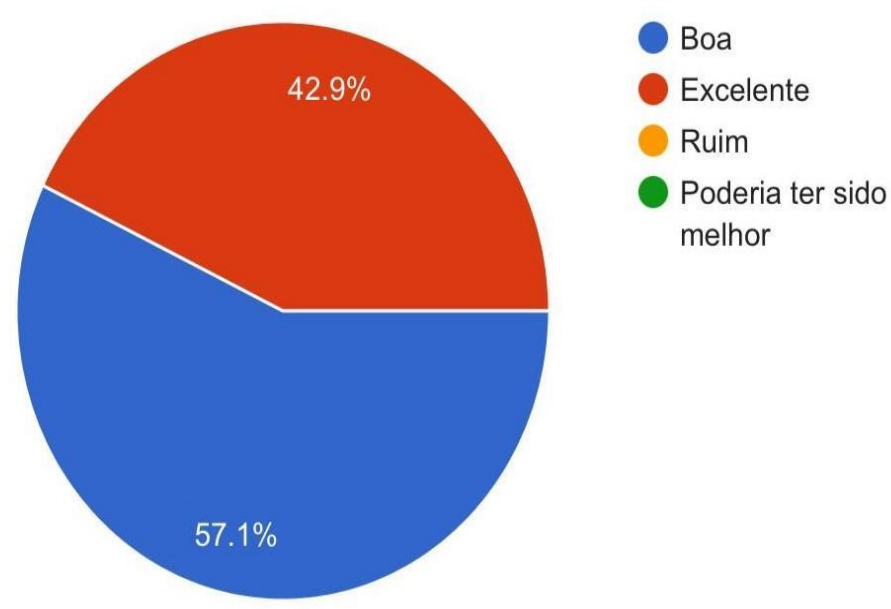

Fonte: As autoras, acervo da pesquisa.

Outro elemento perceptível na avaliação realizada pelo formulário, referiu-se ao interesse maior dos participantes pelas dicas de preparação para vestibulares, com ênfase no ENEM - Exame Nacional do Ensino Médio. Assim, a partir do mês de outubro o grupo passou a priorizar dicas para vestibulandos, seja por meio da indicação de endereços virtuais de páginas ou Website com conteúdo de qualidade detectados na internet; seja pelo envio de materiais produzidos pelas próprias mediadoras.

Conforme exemplificado a seguir, ocorreu a disposição de uma sequência de vídeos explicativos das 5 competências avaliadas no ENEM que foram produzidos pela professora coordenadora em virtude da necessidade dos participantes do projeto apontados no questionário aplicado: 
Figura 4: Link de vídeos sobre competências avaliadas na Redação do Enem

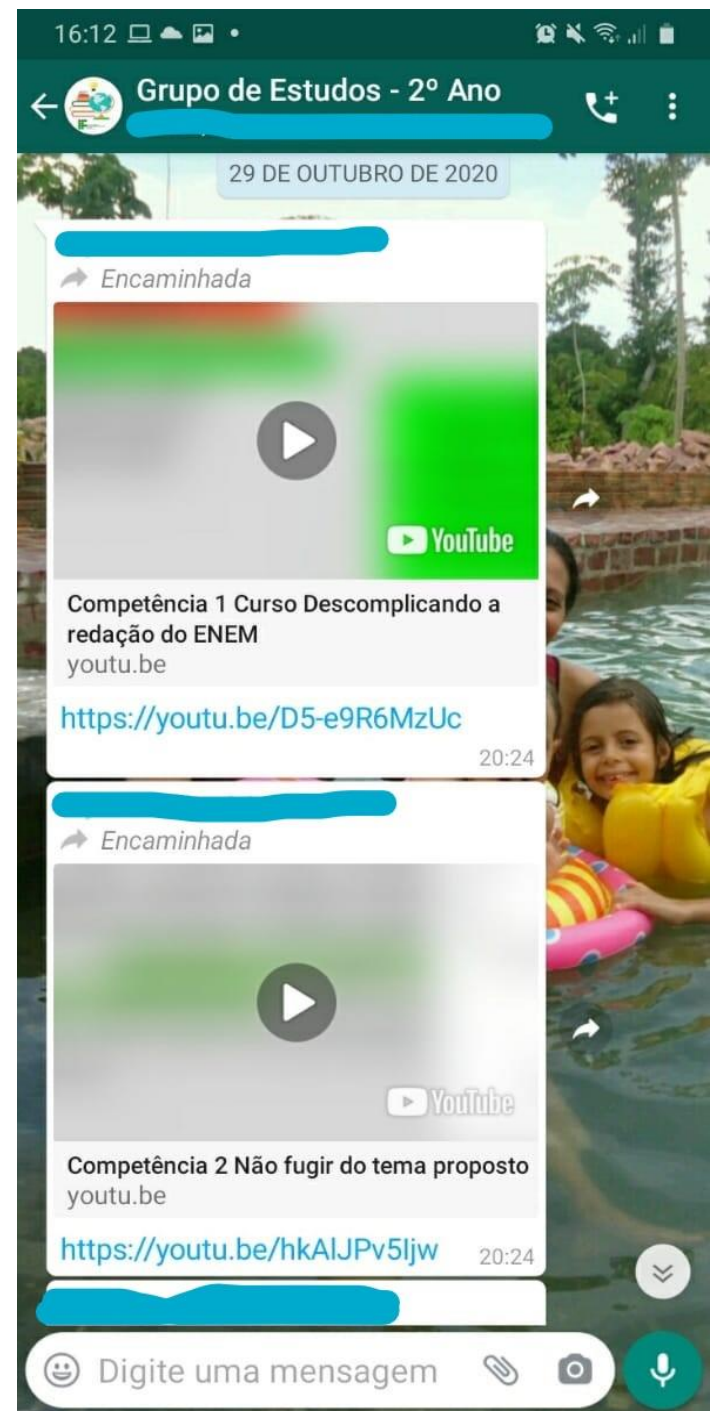

III

Fonte: As autoras, acervo da pesquisa.

Por meio do resultado obtido no questionário realizado com os estudantes, pode-se captar também opiniões positivas sobre a perspectiva do Grupo de estudo quanto aos temas abordados e com relação a integração grupal: 
Figura 5: O que você mais gostou durante a sua participação no grupo?

\author{
A disposição e atenção dos organizadores para com \\ todos os integrantes! \\ Pessoal muito disposto para ajudar as necessidades \\ dos colegas,e sempre está disponível para qualquer \\ dúvida, independente de qualquer coisa! \\ As dicas de estudo mandadas com frequência. \\ ter insigts diferente ao meu acabando aprendendo \\ ainda mais,sem que eu precisa-se ficar imaginando \\ ou buscando em outros lugares. \\ Os vários temas abordados \\ As dicas que foram postadas. \\ As indicações de estudo e as perguntas (으
}

Fonte: As autoras, acervo da pesquisa.

O projeto de Mediação virtual iniciou sua execução no mês de setembro de 2020 e teve seu encerramento no mês de janeiro de 2021, logo após as aplicações do ENEM. Desse modo, após a finalização das atividades do grupo de Estudo, as mediadoras (estudante e professora coordenadora) ficaram responsáveis em terminar o relatório final das atividades desenvolvidas.

\title{
CONSIDERAÇÕES FINAIS
}

Neste artigo abordou-se um relato de experiência acerca do desenvolvimento de um Grupo de estudo virtual durante a Pandemia da COVID-19. A prática alicerçada no sistema de trabalho em grupo, autodirigido, proposto por Murphy e Lick (2005) objetivou auxiliar estudantes do 
ensino médio na construção de uma comunidade autônoma, estimulando a aprendizagem de conteúdos diversos, superando as dificuldades impostas pelo isolamento social.

Pode-se perceber que a atividade desenvolvida por intermédio do WhatsApp foi relevante no que diz respeito a manter as relações pessoais e assegurou maior motivação no processo de aprendizagem durante o período de ensino remoto. A interação e troca de experiências possibilitou o conhecimento de novas perspectivas dos estudantes do grupo. Vale salientar que todos os participantes passaram a ser vistos como seres de potencialidades, já que cada um deveria participar ativamente do grupo, de modo a complementar o repertório de conhecimentos de si e dos outros.

A metodologia participativa possibilitou o protagonismo dos estudantes, colaborando para o desenvolvimento pleno das múltiplas habilidades. Outrossim, a orientação da professora orientadora e a liderança da estudante mediadora permitiu que as discussões sempre fossem bem encaminhadas, de maneiras que todos praticaram a escuta do outro, ao mesmo tempo que sanavam dúvidas em conjunto.

A partir do resgate da literatura, o estudo compartilhado por todos os participantes do grupo, corroborou para a assertiva de que o caminho do conhecimento pode ser mais interessante do que se pensa quando realizado em comunidade, de maneira que o aplicativo de WhatsApp pode possibilitar um cenário interacional, promovendo um espaço de sociabilidade, suprindo grande parte da expectativa juvenil.

Por fim, o Grupo de Estudo virtual apresentou-se como instrumento pedagógico significativo durante a suspensão das atividades presenciais, desenvolvendo acolhimento, autonomia e sociabilidade, ao mesmo tempo que favoreceu a um processo de aquisição de conhecimento curricular, construído por todos os envolvidos.

\section{REFERÊNCIAS BIBLIOGRÁFICAS}

BARROS, Marilisa Berti de Azevedo et al. Relato de tristeza/depressão, nervosismo/ansiedade e problemas de sono na população adulta brasileira durante a pandemia de COVID-19. Epidemiol. Serv. Saúde, Brasília, v. 29, n. 4, e2020427, set, 2020. Disponível em < 
http://scielo.iec.gov.br/scielo.php?script=sci_arttext\&pid=S1679-49742020000400021 > Acessos em 30 jan. 2021 Epub 20-Ago-2020. http://dx.doi.org/10.1590/s167949742020000400018.

DAYRELL, Juarez. A escola "faz" as juventudes? Reflexões em torno da socialização juvenil. Educação \& Sociedade, Campinas, vol. 28, n. 100 - Especial, p. 1105-1128, out. 2007. Disponível em < https://www.scielo.br/j/es/a/RTJFy53z5LHTJjFSzq5rCPH/?lang=pt > Acesso em 31 jan. de 2021.

FREIRE, Paulo. Pedagogia da autonomia: saberes necessários à prática educativa. São Paulo: Paz e Terra, 1996.

GARDNER, Howard. Estruturas da mente: a teoria das inteligências múltiplas. Trad. Sandra Costa. Porto Alegre: Artes Médicas Sul, 1994.

GATES, Bill. A Estrada do Futuro. 1ª Edição, São Paulo: Companhia das Letras, 1995.

MURPHY, Carlene U.; LICK, Dale W. Whole-Faculty Study Groups: Creating professional learning communities that target student learning. 3rd ed. Thousand Oaks, CA: Corwin. 2005.

SANTOS, Edméa. Educação online para além da EAD: um fenômeno da cibercultura. Actas do X Congresso Internacional Galego-Português de Psicopedagogia. Braga: Universidade do Minho, 2009, p. 5658-5671. Disponível em: < https://www.educacion.udc.es/grupos/gipdae/documentos/congreso/xcongreso/pdfs/t12/t12c4 27.pdf $>$ Acesso em 29 jan. 2021.

TORRES, Patrícia Lupion; IRALA, Esrom Adriano F. Aprendizagem colaborativa: Teoria e prática. In Metodologias para a produção do conhecimento: da concepção à prática. org. Patrícia Lupion Torres. Coleção Agrinho. Curitiba: SENAR-PR, p 64- 96, 2015. Disponível em:

https://www.agrinho.com.br/ebook/senar/livro1/files/MetodologiaProducaoConhecimento.pdf $>$ Acesso em 28 abr 2021.

LEAL, Breno. A importância dos grupos de estudos na formação profissional. UNINASSAU. Notícias: Educação. 09 de julho de 2020. Disponível em: < https://www.uninassau.edu.br/noticias/importancia-dos-grupos-de-estudos-na-formacaoprofissional >. Acesso em 28 jan. 2021.

VYGOTSKY, Lev Semionovitch. A formação social da mente. São Paulo: Martins Fontes, 1991.

Este é um artigo de acesso aberto distribuído sob os termos da Licença Creative Commons Atribuição Não Comercial-Compartilha Igual (CC BY-NC- 4.0), que permite uso, distribuição e reprodução para fins não comerciais, com a citação dos autores e da fonte original e sob a mesma licença. 